Herzschr Elektrophys 2018 $29: 355-361$ https://doi.org/10.1007/s00399-018-0602-y Received: 25 September 2018

Accepted: 9 October 2018

Published online: 31 October 2018

(c) The Author(s) 2018

CrossMark

\section{F. V. Y. Tjong'}

${ }^{1}$ AMC Heart Center, Department of Clinical and Experimental Cardiology, Amsterdam University Medical Center, Location Academic Medical Center, University of Amsterdam, Amsterdam, The Netherlands

${ }^{2}$ Boston Scientific Corporation, St. Paul, USA

\title{
The modular cardiac rhythm management system: the EMPOWER leadless pacemaker and the EMBLEM subcutaneous ICD
}

\section{Introduction}

For many decades, cardiac electrical implantable devices (CIED) have been the cornerstone therapy for patients with brady- and tachyarrhythmias [1-4]. Despite many years of innovation and device development, these systems are still associated with a significant amount of acute and chronic complications, of which many are related to the "weakest link" of these systems: the transvenous lead [5-7]. Paradigm shifting technologies have been introduced to eliminate the need for a transvenous lead. First, in 2008, the subcutaneous implantable cardioverter defibrillator (S-ICD) was introduced [8], a device placed fully subcutaneously, limiting intracardiac hardware. Improvements in battery technology and advanced electrical circuitry brought about leadless pacemakers, miniaturized self-contained intracardiac single-chamber pacemakers delivered in the right ventricle through a percutaneous transfemoral catheter based approach [9, 10]. Two systems have been clinically available now for several years and showed clinical efficacy and safety [9-13]. However, existing leadless pacing systems and the S-ICD are only available for patients requiring single-chamber right ventricular (RV) pacing or shock-only defibrillation therapy, respectively. Combined use of both types of devices could bring the potential benefits of this leadless approach to a larger patient population. Adding antitachycardia pacing (ATP) to this combined system would enable even larger patient groups to potentially benefit [14]. These combined device systems require safe and reliable device-device communication and enable a novel treatment concept of modular cardiac rhythm management (mCRM) therapy, in which device therapy could be further personalized to the current and future patients' needs. The first mCRM system is presented in this review and consists of a communicating and the EMPOWER ${ }^{\mathrm{TM}}$ leadless cardiac pacemaker (LCP; both Boston Scientific), which are shown in - Fig. 1. To date, this is the first system consisting of communicating independent cardiac devices for synchronized therapy application.

\section{Intrabody communication and the modular cardiac rhythm management system}

Beginning in the 1990s, researchers became interested in the possibilities of intrabody communication involving implanted devices in various forms and using various communication modalities [15-17]. It later became clear that one of the most energy efficient modalities for communication between implanted de- vices was galvanic coupling, or communication using the conductive properties of the body [18-20]. Through galvanic coupling, one implanted device transmits low-energy electrical signals, such as via alternating current, which is detected by two electrodes on the receiving device. The advantages of galvanic coupling over other communication modalities such as radiofrequency (RF) communication include not only lower energy requirements but also lower signal losses in tissue. The disadvantages of galvanic coupling include comparatively lower rates of data transmission and the potential for larger null spaces due to relative physical orientation of device electrodes.

Due to the power efficiency and less lossy nature in human tissue, galvanic coupling, or "conducted" communication, was selected as the communication modality to be used for device-device communication in the $\mathrm{mCRM}$ system. A secondary design goal was to allow existing implanted S-ICDs to be upgraded via firmware, with no change to the hardware within the system, to enable the ability to communicate. The advantage of this strategy is to allow access to this new technology, the modular addition of intracardiac therapy, for patients with an EMBLEM platform S-ICD system without the need to explant and replace the S-ICD pulse generator. The compromise is to utilize only unidirec- 

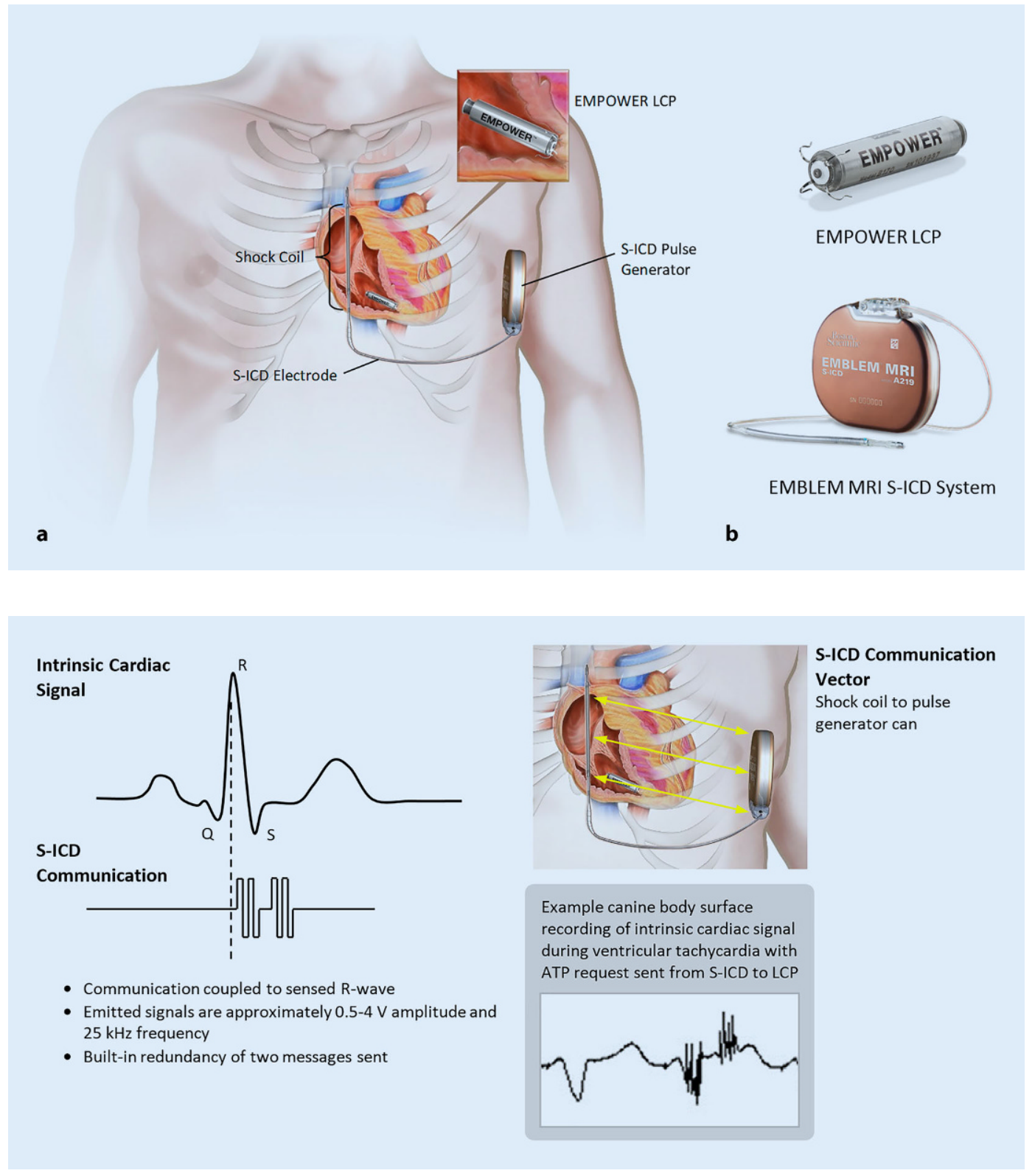

Fig. $1<$ The modular cardiac rhythm management (mCRM) system. a Depiction of implanted mCRM system. b Close-up images of EMPOWER and EMBLEM MRI devices (not to scale). $S-I C D$ subcutaneous implantable cardioverter-defibrillator, LCP leadless cardiac pacemaker. ( 2017 Boston Scientific Corporation or its affiliates. All rights reserved. Used with permission of Boston Scientific Corporation

Fig. $2<$ Device-device communication of the mCRM system. Depiction of how communication messages are sent from S-ICD to EMPOWER LCP via conducted signals. The EMPOWER LCP senses the conducted signals via its cathode and anode, which are also used for sensing intrinsic cardiac signals. $m C R M$ modular cardiac rhythm management, $S$-ICD subcutaneous implantable cardioverter-defibrillator, LCP leadless cardiac pacemaker, ATP antitachycardia pacing tional conducted communication from S-ICD to LCP, which allows access to ATP therapy but limits additional features that could come from this pairing to future generations of S-ICD pulse generator where bidirectional communication would be possible.

To accomplish the objective of adding conducted communication ability to the S-ICD system without updating its hardware, existing circuitry in the S-ICD pulse generator, normally utilized to check shock circuit integrity, was repurposed to send bursts of approximately $25 \mathrm{kHz}$ pulses from the shock coil of the S-ICD electrode to the S-ICD pulse generator can. These pulses are low in voltage amplitude $(<5 \mathrm{~V}$ emitted) and are sent in a proprietary pattern that can be recognized by the LCP and is distinct from various levels of signal noise that may be sensed by the LCP. The pattern of pulses constituting a full communication message from S-ICD requires less than $40 \mathrm{~ms}$ in duration, though to provide redundancy two messages are sent in series to help mitigate risk of failed receipt by the LCP. Two full communication messages back-to-back require less than $135 \mathrm{~ms}$ in duration, which is short enough to fit within a standard pacemaker cardiac sensing refractory window. S-ICD communication messages are sent coincident with the $\mathrm{R}$-wave of the cardiac cycle to avoid oversensing of these communications on the LCP's cardiac sensing channel. 0 Fig. 2 depicts the S-ICD-to-LCP communication details.

Since the vector used by the S-ICD to communicate electrical signals is from the shock coil to the pulse generator can, and the LCP senses these conducted signals via its cathode and anode, the spatial orientation of the LCP within the S-ICD communication vector can impact the ability of the LCP to sense the transmitted signals from S-ICD. Theoretically, the 
highest communication signal amplitude sensed by the LCP is when its main axis is aligned with the S-ICD communication vector as shown in - Fig. 2. Conversely, the lowest communication signal amplitude sensed by the LCP is when its main axis is perpendicular to the S-ICD communication vector, or when the LCP is approximately parallel with the S-ICD shock coil when the implanted system is viewed in an anterior-posterior view under fluoroscopy. The orientation of the LCP relative to the S-ICD communication vector in humans is expected to have a favorable position in relation to the communication vector, with a preferred device deployment in the right ventricular apicoseptal region. Implantation of the LCP in the free wall of the right ventricle is not recommended because of the less favorable device orientation and the higher potential risk of cardiac perforation. A previous report evaluated the device orientation of other leadless pacemakers in humans (e.g., [21]). However, if the EMPOWER LCP were to be in an unfavorable orientation, the combination of S-ICD communication message redundancy and the motion of the heart during the cardiac cycle is intended to mitigate the possibility of the S-ICD communication not being received by the LCP.

In terms of tachyarrhythmia and bradyarrhythmia sensing and therapy, the S-ICD and LCP elements of the mCRM system act independently from each other except for antitachycardia pacing (ATP) therapy. For ATP, S-ICD employs the same sensing and detection criteria to declare a tachyarrhythmia episode as those used in market-approved A209 and A219 model S-ICDs. However, the same model S-ICD with firmware upgrade and mCRM communication feature activated can request the EMPOWER LCP to perform ATP therapy according to programmed parameters. These programmable parameters include the number of ATP attempts within a programmed S-ICD tachyarrhythmia rate zone, scheme of ATP (Burst or Scan), ATP coupling/ burst interval, and number of pulses per ATP attempt. Depending on the rate zone of the S-ICD in which tach-

Herzschr Elektrophys 2018 - 29:355-361 https://doi.org/10.1007/s00399-018-0602-y

(c) The Author(s) 2018

\section{F. V. Y. Tjong • B. E. Koop}

\section{The modular cardiac rhythm management system: the EMPOWER leadless pacemaker and the EMBLEM subcutaneous ICD}

\section{Abstract}

Cardiac implantable electronic devices have been successfully treating patients with brady- and tachyarrhythmias for decades. However, there are still significant complications related to this therapy modality, many related to the transvenous lead. Paradigm-shifting technologies, such as the subcutaneous implantable cardioverter-defibrillator (S-ICD) and leadless cardiac pacemakers $(\mathrm{LCP})$, have emerged to address these complications. The novel modular cardiac rhythm management (mCRM) system, consisting of a communicating antitachycardia pacing-enabled LCP and
S-ICD, is the first system to integrate wireless intrabody communication between devices to allow for coordination of leadless pacing and defibrillator therapy delivery. In this review, the design and concept of the mCRM system are presented and available evidence is summarized.

\section{Keywords}

Tachycardia $\cdot$ Leadless pacing $\cdot$ Antitachycardia pacing $\cdot$ Subcutaneous implantable cardioverter-defibrillator - Arrhythmias, cardiac

\section{Das modulare Herz-Rhythmus-Management-System: der EMPOWER sondenlose Herzschrittmacher und der EMBLEM subkutane ICD}

\section{Zusammenfassung}

Seit Jahrzehnten werden kardiale implantierbare elektronische Devices erfolgreich bei Patienten mit Brady- und Tachyarrhythmien eingesetzt. Bei dieser Therapie gibt es jedoch noch immer bedeutende Komplikationen, von denen viele auf die transvenöse Elektrode zurückzuführen sind. Ein Paradigmenwechsel entstand durch Technologien wie den subkutanen implantierbaren KardioverterDefibrillator (S-ICD) sowie sondenlose Herzschrittmacher (LCP), die entwickelt wurden, um diese Komplikationen zu adressieren. Das neue modulare HerzRhythmus-Management(mCRM)-System, bestehend aus einem kommunizierenden LCP mit antitachykarder Stimulation und einem S-ICD, ist das erste System, welches die kabellose Kommunikation zwischen den Devices innerhalb des Körpers integriert, um die Koordination der sondenlosen Schrittmacher- und Defibrillatortherapie zu ermöglichen. In diesem Review werden Design und Konzept des mCRM-Systems vorgestellt sowie die verfügbare Evidenz zusammengefasst.

\section{Schlüsselwörter}

Tachykardie · Sondenlose Schrittmacher . Antitachykarde Schrittmacher - Subkutaner implantierbarer Kardioverter-Defibrillator . Kardiale Arrhythmien yarrhythmia is occurring, ATP therapy can be requested of the LCP, including multiple times, before moving to charging for shock therapy, or ATP therapy can be requested and applied in parallel to charging for shock. After the ATP communication request by the S-ICD there is a programmed delay of about $4 \mathrm{~s}$ before the S-ICD starts sensing the intrinsic rhythm to allow ATP therapy to be applied by the LCP and ensure ATP is not included in the subsequent tachydetection by the S-ICD.

\section{Data from acute and chronic animal implants}

Data regarding successful S-ICD/LCP device-device communication and coordination of ATP during simulated ventricular tachycardia in an ovine model was first reported in 2016 [22]. A larger animal study was published later with more extensive evaluations of the technology [23]. In the latter study, acute and chronic animal implants of the mCRM system were completed to test the pacing and sensing performance of the EMPOWER 
Table 1 Acute and 3-month EMPOWER LCP performance showing favorable pacing and sensing performance over the course of the study. Values are $n(\%)$ or mean \pm standard deviation

\begin{tabular}{|c|c|c|c|c|c|c|c|}
\hline & \multirow{2}{*}{\multicolumn{3}{|c|}{$\begin{array}{l}\text { Acute Performance }(n=40) \\
\text { Baseline }\end{array}$}} & \multicolumn{4}{|c|}{ 3-Month Performance $(n=23)$} \\
\hline & & & & \multicolumn{4}{|l|}{ Canine } \\
\hline & Ovine $(n=8)$ & Swine $(n=5)$ & $\begin{array}{l}\text { Canine } \\
(n=27)\end{array}$ & 7 Days & 28 Days & 90 Days & $p$ Value \\
\hline Implant Success & $8(100)$ & $5(100)$ & $26(96)$ & - & - & - & - \\
\hline \multicolumn{8}{|l|}{ LCP Position } \\
\hline RV Apex & $8(100)$ & $4(80)$ & $12(46)$ & - & - & - & - \\
\hline RV Apical Septum & 0 & 0 & $14(54)$ & - & - & - & - \\
\hline RV Outflow Tract & 0 & $1(20)$ & 0 & - & - & - & - \\
\hline LCP Electrical Performance & $(n=8)$ & $(n=5)$ & $(n=26)$ & $(n=23)$ & $(n=23)$ & $(n=23)$ & \\
\hline Pacing Threshold, $\mathrm{V}$ at $0.5 \mathrm{~ms}$ & $1.10 \pm 0.81$ & $0.53 \pm 0.49$ & $0.37 \pm 0.19$ & $0.56 \pm 0.37^{b}$ & $0.54 \pm 0.30^{b}$ & $0.72 \pm 0.45^{\mathrm{b}, \mathrm{c}}$ & $<0.001$ \\
\hline R-Wave Amplitude, $\mathrm{mV}$ & $6.6 \pm 1.4$ & $28.3 \pm 5.8$ & $25.8 \pm 5.1^{d}$ & $26.3 \pm 6.8^{d}$ & $25.0 \pm 9.4^{d}$ & $23.3 \pm 9.4$ & $<0.001$ \\
\hline Impedance, $\Omega$ & $665 \pm 225$ & $753 \pm 118$ & $826 \pm 171^{d}$ & $785 \pm 129^{d}$ & $827 \pm 105^{d}$ & $728 \pm 141^{c}$ & 0.04 \\
\hline LCP Post Shock Performance & $(n=8)$ & $(n=2)$ & $(n=1)$ & & & $(n=7)$ & \\
\hline $\begin{array}{l}\text { Pre- to Post Shock Change in } \\
\text { Pacing Threshold, } V \text { at } 0.5 \mathrm{~ms}\end{array}$ & $0.0 \pm 0.5$ & $0.1 \pm 0.1$ & 0 & - & - & $0.0 \pm 0.1$ & - \\
\hline $\begin{array}{l}\text { Pre- to Post-Shock Change in } \\
\text { Impedance, W }\end{array}$ & $18 \pm 49$ & $26 \pm 40$ & 5 & - & - & $-48 \pm 58$ & - \\
\hline \multicolumn{8}{|c|}{$\begin{array}{l}\text { Table reprinted from Tjong et al. [23] with permission from the publisher } \\
L C P \text { leadless cardiac pacemaker, } R V \text { right ventricle } \\
\text { a } p \text { value between baseline and } 90 \text { days, for pacing threshold and impedance tested with the Student } t \text { test, for } R \text { wave calculated with a linear regression } \\
\text { analysis } \\
\text { bPacing threshold data from } 3 \text { animals were excluded because the LCP prototypes did not have steroid-eluting electrode } \\
{ }^{9} \text { Impedance and pacing threshold data from } 1 \text { animal were excluded due to suspected device malfunction at day } 90 \\
{ }^{d} \text { R-wave and impedance data from } 7 \text { animals at baseline, } 9 \text { animals at day } 7 \text {, and } 7 \text { animals at day } 28 \text { were excluded due to programmer software malfunction }\end{array}$} \\
\hline
\end{tabular}

LCP, as well as the communication and system performance of the S-ICD and LCP together. Data from acute implants in multiple animal species (canine, ovine, and swine) and up to 90 days of chronic implant in canines were reported, with LCP pacing and sensing data as shown in - Table 1.

Data obtained on voltage threshold for successful communication from S-ICD to LCP was also obtained in canines for three postures in the same 3-month study and is shown in - Fig. 3. The data were taken with respect to the voltage amplitude setting in the S-ICD pulse generator used to generate the communication pulses. This setting is not equal to the voltage emitted by the device, which is approximately $30-75 \%$ lower than the voltage amplitude setting (depending on the setting used).

These results are important for understanding the chronic stability of device-device communication for the mCRM system in vivo. Specifically, the results show that, on average, the communication threshold was low (signal margin for successful device-device communication was high) and stable throughout the 3-month study. Further, any differences in communication threshold between the three postures tested were small and not of practical significance relative to the signal margin that exists if the S-ICD was programmed to its nominal amplitude setting. Indeed, there is little incentive to program the system to a communication setting lower than the nominal value as there is expected to be very low impact to S-ICD longevity (days or weeks depending on the number of ambulatory ATP episodes) to send communications during the device lifetime, regardless of amplitude setting.

Using data from the same 3-month animal study, an analysis of the impact of EMPOWER LCP spatial orientation on communication threshold was conducted and reported in 2018 [24]. Included in the same evaluation was a retrospective analysis of patients from a single center implanted with either an S-ICD system or a commercially available leadless pacemaker. This analysis was per- formed to utilize the data from the animal study to determine the favorability of the LCP spatial orientation relative to the $\mathrm{S}$-ICD communication vector in human anatomy. An example of the communication vector between S-ICD and LCP and the orientation of the LCP within this vector is shown in 0 Fig. 4 . The findings from the animal data showed that a when the LCP is approximately parallel with the S-ICD shock coil in an anterior-posterior view under fluoroscopy, the communication threshold trends higher but the effect was moderate. It is hypothesized that the practice of sending two communication messages in series from the S-ICD helps alleviate the possibility of communication failure. Additionally, the human body is not a homogenous conductive medium; organs such as the lungs likely cause a divergence of electric field orientation created by the S-ICD communication pulses which may allow a high tolerance for many LCP spatial orientations S-ICD relative to the communication vector. Overall, the angle ( $\alpha$, - Fig. 4) of the LCP axis relative to the 


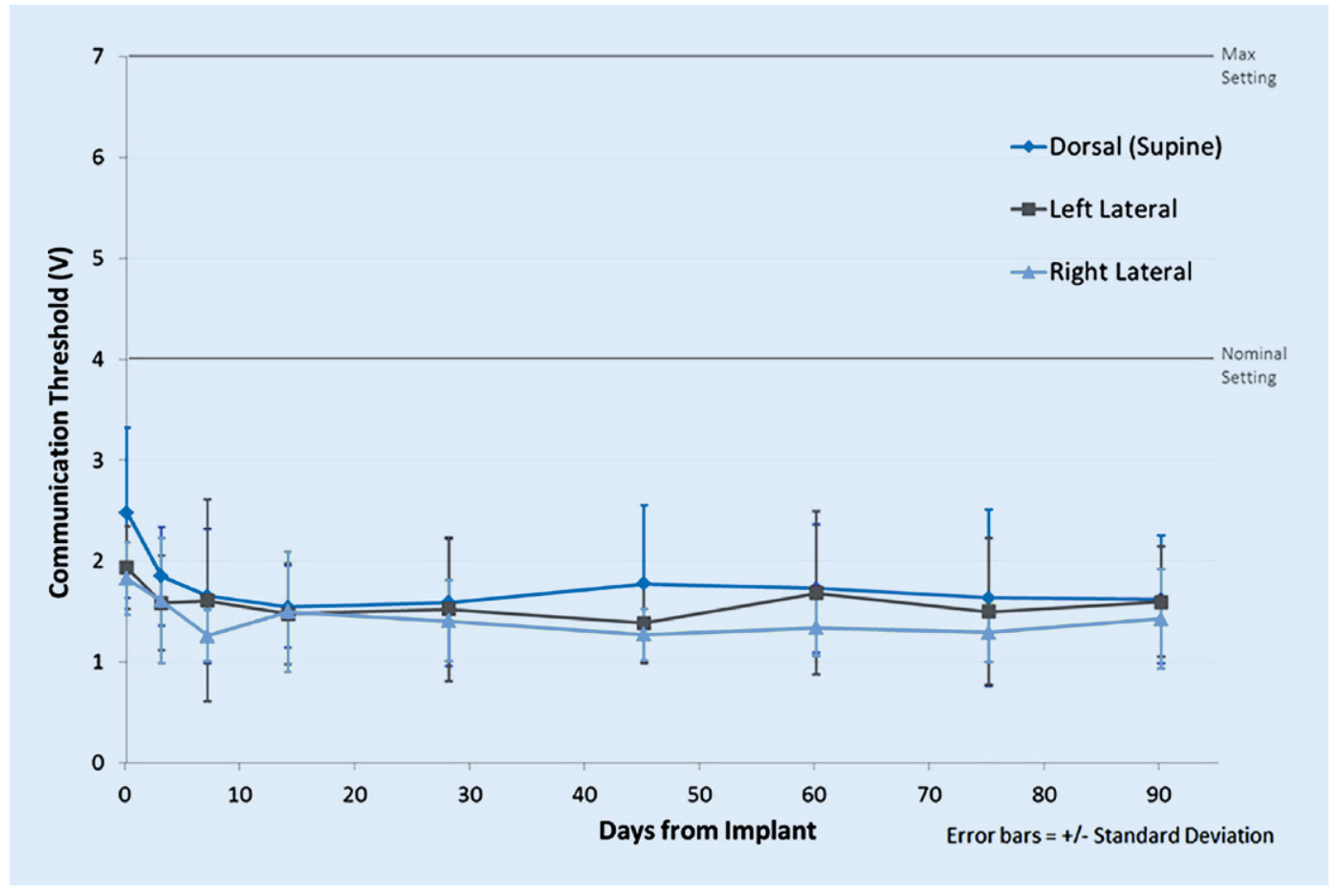

Fig. $3<$ Device-device communication thresholds. Threshold for successful S-ICD to LCP communication, where the threshold is based on the voltage amplitude setting in the S-ICD used for sending the communication pulses. This is not equal to the voltage emitted by the $S-I C D$, which is generally $30-75 \%$ lower. The communication voltage amplitude setting can range from 1 to $7 \mathrm{~V}$, with a nominal setting of $4 \mathrm{~V}$. S-ICD subcutaneous implantable cardioverter-defibrillator, LCP leadless cardiac pacemaker. Reprinted from Tjong et al. [23] with permission from the publisher

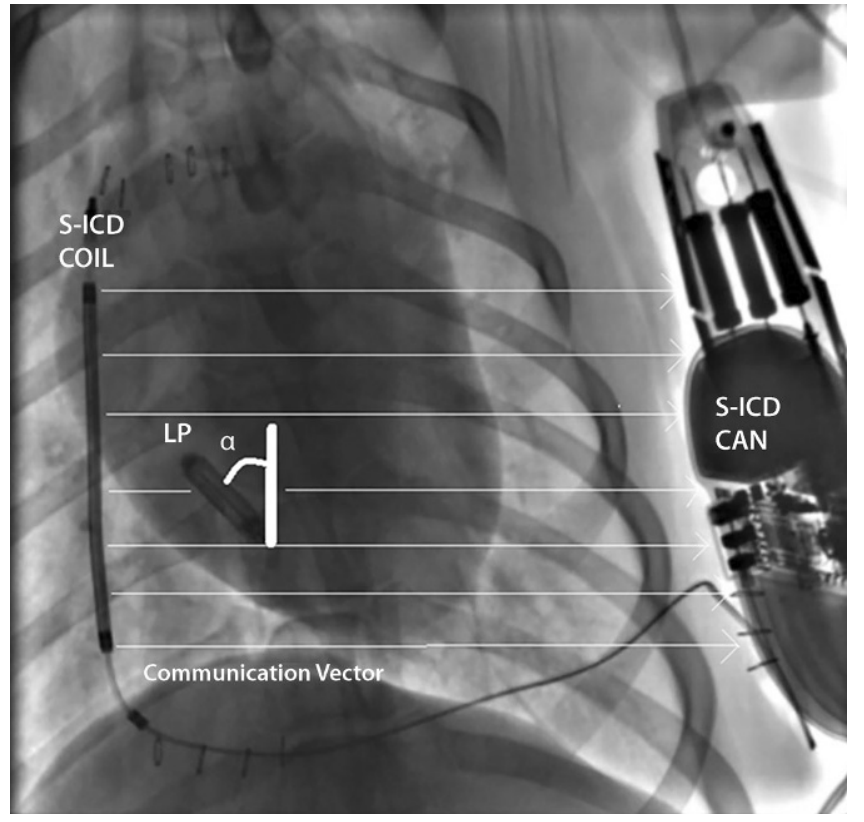

S-ICD shock coil in canines was found to be $25^{\circ}$ on average, while in humans the mean angle was $56^{\circ}$. This result may predict an even higher signal margin for communication when the mCRM system is evaluated in humans in the near future, though it is acknowledged there are other important factors such as torso size which can impact communication success.
Fig. $4 \triangleleft$ Device orientation in communication vector between S-ICD and LCP. This fluoroscopy image shows the measurements of the orientation vector between S-ICD lead and can, with the orientation of the LCP within this vector (angle a). S-ICD subcutaneous implantable cardioverter-defibrillator, LP leadless pacemaker. Reprinted from Tjong et al. [23] with permission from the publisher

\section{Discussion}

Modular therapy is the idea that one can tailor implantable medical device therapy to the specific needs of the patient throughout their lifetime so that the patient receives only the device(s) they need, only when needed. Medical devices inherently involve risks to the patient related to implantation and to continuing operation in the body. Ideally for the pa- tient the benefits of the implanted devices far outweigh the risks. However, some patients who would be eligible to receive an implanted S-ICD system instead receive a transvenous ICD system despite having no immediate need for pacing therapy or ATP. This may be a decision made by the physician with a view to the possibility the patient would need these therapies in the future. The downside of this decision is the patient receives a system that has disadvantages compared to S-ICD: Intracardiac leads which may fail, infection pathways to the heart, and complications that occur acutely or chronically due to implantation within the heart.

With the advent of the mCRM system and wireless communication capabilities of implants, there will be an alternative approach: Implant the S-ICD system in eligible patients now and implant the EMPOWER LCP later only if the patient develops a therapeutic need for the device. The number of patients who develop such a need are expected to be low [25], meaning more patients can benefit from a less invasive device therapy strategy. As further components of this modular system are developed in the future, further therapies will be available for application in a modular fashion as the patient's disease 
state progresses, heralding an era of truly personalized device medicine.

\section{Limitations and next steps}

The main limitations in understanding the safety and effectiveness of the MCRM system is that only animal data exist currently. Though animal evaluations in multiple models can serve as a useful surrogate when human evaluation is not available, there remain aspects of any animal model which cannot fully replicate human anatomy and environment. Human clinical studies of the EMPOWER LCP as a standalone device and the mCRM system in humans are expected to commence in 2019. Future iterations of the mCRM system are expected to include leadless devices for pacing other chambers of the heart to provide dual chamber pacing therapy or cardiac resynchronization therapy, as standalone devices and in coordination with a co-implanted S-ICD. Future iterations of S-ICD system are also expected to allow bidirectional communication with other leadless devices in the mCRM system, as well as new algorithms to allow sensing verification, new discrimination capabilities and new features via device-device communication.

\section{Practical conclusion}

- Complications with the transvenous lead have been overcome using S-ICD and LCP.

- A modular cardiac rhythm management (mCRM) system, consisting of a communicating antitachycardia pacing-enabled EMPOWER ${ }^{\mathrm{TM}} \mathrm{LCP}$ and EMBLEM $^{\mathrm{Tm}}$ platform S-ICD system, allows for coordination of leadless pacing and defibrillator therapy delivery.

- Firmware can be upgraded in implanted S-ICDs without explantation or replacement of the pulse generator.

- Acute and 3-month data regarding device-device communication and coordination of ATP during simulated ventricular tachycardia in animal studies are promising.
- Advances include the possibility to implant the S-ICD system in eligible patients now and implant the EMPOWER LCP later only if the patient develops a therapeutic need for the device.

- Human clinical studies with the EMPOWER LCP and the MCRM system are expected in 2019.

\section{Corresponding address}

\section{F. V. Y. Tjong, MD, PhD}

AMC Heart Center, Department of Clinical and Experimental Cardiology, Amsterdam University Medical Center, Location Academic Medical Center, University of Amsterdam Amsterdam, The Netherlands f.v.tjong@amc.nl

\section{Compliance with ethical guidelines}

Conflict of interest. F.V.Y. Tjong reports consulting fees from St. Jude Medical, Boston Scientific. B.E. Koop is an employee of Boston Scientific.

This article does not contain any studies with human participants or animals performed by any of the authors.

Open Access. This article is distributed under the terms of the Creative Commons Attribution 4.0 International License (http://creativecommons.org/licenses/by/ 4.0/), which permits unrestricted use, distribution, and reproduction in any medium, provided you give appropriate credit to the original author(s) and the source, provide a link to the Creative Commons license, and indicate if changes were made.

\section{References}

1. Tracy CM, Epstein AE, Darbar D et al (2012) 2012 ACCF/AHA/HRS focused update of the 2008 guidelines for device-based therapy of cardiac rhythm abnormalities: a report of the American college of cardiology foundation/American heart association task force on practice guidelines. J Am Coll Cardiol 60:1297-1313

2. Moss AJ, Hall WJ, Cannom DS et al (1996) Improved survival with an implanted Defibrillator in patients with coronary disease at high risk for ventricular arrhythmia. Multicenter automatic defibrillator implantation trial investigators. N Engl J Med 335:1933-1940

3. Moss AJ, Zareba W, Hall WJ et al (2002) Multicenter automatic defibrillator implantation trial II. Prophylactic implantation of a defibrillator in patients with myocardial infarction and reduced ejection fraction. N Engl J Med 346:877-883

4. Bardy GH, Lee KL, Mark DB et al (2005) Amiodarone or an implantable cardioverter-defibrillator for congestive heartfailure. N Engl J Med 352:225-237
5. Kirkfeldt RE, Johansen JB, Nohr EA, Jørgensen OD, Nielsen JC (2014) Complications after cardiac Implantable electronic device Implantations: an analysis of a complete, nationwide cohort in Denmark. Eur Heart J 35:1186-1194

6. Van der Heijden AC, Borleffs CJ, Buiten MS et al (2015) The clinical course of patients with Implantable Cardioverter-Defibrillators: extended experience on clinical outcome, device replacements, and device-related complications. Heart Rhythm 12:1169-1176

7. Udo EO, Zuithoff NP, van Hemel NM et al (2012) Incidence and predictors of short- and longterm complications in pacemaker therapy: the FOLLOWPACE study. Heart Rhythm 9:728-735

8. Bardy GH, Smith WM, Hood MA et al (2010) An entirely subcutaneous implantable cardioverterdefibrillator. N Engl J Med 363:36-44

9. Reddy VY, Exner DV, Cantillon DJ et al (2015) LEADLESS II study investigators percutaneous implantation of an entirely intracardiac leadless pacemaker. NEngl J Med 373:1125-1135

10. Reynolds D, Duray GZ, Omar R et al (2016) Micra transcatheter pacing study group A leadless intracardiac transcatheter pacing system. N Engl J Med 374:533-541

11. Burke MC, Gold MR, Knight BP et al (2015) Safety and efficacy of the totally subcutaneous implantable defibrillator: 2-year results from a pooled analysis of the IDE study and EFFORTLESS registry. J Am Coll Cardiol 65:1605-1615

12. Boersma LV, Barr CS, Burke MC et al (2017) Performance of the subcutaneous implantable cardioverter-defibrillator in patients with a primary prevention indication with and without a reduced ejection fraction versus patients with a secondary prevention indication. Heart Rhythm 14(3):367-375

13. El-Chami MF, Al-Samadi F, Clementy N et al (2018) Updated performance of the micra transcatheter pacemaker in the real-world setting: a comparison to the investigational study and a transvenous historical control. Heart Rhythm. https://doi.org/ 10.1016/j.hrthm.2018.08.005

14. Kleemann T, Strauss M, Kouraki K, Zahn R (2015) Clinical course and prognostic relevance of antitachycardia pacing-terminated ventricular tachyarrhythmias in implantable cardioverterdefibrillator patients. Europace 17:1068-1075

15. Zimmerman TG (1995) Personal Area Networks (PAN): Near-Field Intra-Body Communication. PhD thesis. Massachusetts Institute of Technology, MA USA

16. Lindsey DP, McKee EL, Hull ML, Howell SM (1998) A new technique for transmission of signals from implantable transducers. leee Trans Biomed Eng 45(5):614-619

17. Hachisuka K, Nakata A, Takeda T, Terauchi Y, Shiba K, Sasaki K, Hosaka H, Itao K (2003) Development and performance analysis of an intra-body communication device. The $12^{\text {th }}$ International Conference on Transducers, Solid State Sensors, Actuators, and Microsystems, vol 2, pp 1722-1725

18. Ferguson JE, Redish AD (2011) Wireless communication with implanted medical devices using the conductive properties of the body. Expert Rev Med Devices 8(4):427-433

19. TruptiLotlikar Al, Tilak D, Komal R, Prajakata $S$ (2012) Comparison of approaches to intrabody communication. Indian J Comp Sci Eng 3(5):731-736

20. Zhang S, Qin Y, Kuang J, MakPU,PunSH, Vai MI, Liu Y (2014) Development and prospect of Implantable 
intra-body communication technology. J Comput 9(2):463-473

21. Ahmed FZ, Cunnington $C$, Motwani M, Zaidi AM (2017) Totally Leadless Dual-Device Implantation for Combined Spontaneous Ventricular Tachycardia Defibrillation and Pacemaker Function: A First Report. Can JCardiol 33:1066e5-1066e7

22. Tjong FVY, Brouwer TF, Kooiman KM, Smeding L, Koop B, Soltis B, Shuros A, Wilde AAM, Burke MC, Knops RE (2016) Communicating Antitachycardia pacing-enabled leadless pacemaker and subcutaneous implantable defibrillator. J Am Coll Cardiol 67(15):1865-1866

23. Tjong FVY, Brouwer TF, Koop B, Soltis B, Shuros A, Schmidt B, Swackhamer B, Quast AFBE, Wilde AAM, Burke MC, Knops RE (2017) Acute and 3-month performance of a communicating leadless antitachycardia pacemaker and subcutaneous implantable defibrillator. J Am Coll Cardiol 3(13):1487-1498

24. Quast AFBE, Tjong FVY, Koop BE, Wilde AAM Knops RE, Burke MC (2018) Device orientation of a leadless pacemaker and subcutaneous implantable cardioverter-defibrillator in canine and human subjects and the effect on Intrabody communication. Europace. https://doi.org/10. 1093/europace/euy019

25. Boersma L, Barr C, Knops R, Theuns D, Eckardt L, Neuzil P, Scholten M, Hood M, Kuschyk J, Jones P, Duffy E, Husby M, Stein K, Lambiase PD, Investigator Group (2017) Implant and midterm outcomes of the subcutaneous implantable cardioverter-defibrillator registry: the EFFORTLESS study. JAm Coll Cardiol 70(7):830-841 